\title{
ACETONE RECOVERY USING BATCH DISTILLATION
}

\author{
Ebrahim Ali Mohamed Hawaidi ${ }^{1 *}$, Mustafa T. Yagub ${ }^{2}$, and Riyad Ageli Saleh ${ }^{3}$ \\ ${ }^{1,2,3}$ Associated Prof. at Department of Chemical Engineering, Faculty of Engineering in Sabratha, \\ university, Libya.*(email: Ebrhawaidi@gmail.com).
}

\begin{abstract}
This study focuses on determining the feasibility of obtaining maximum mole percentage of acetone ( 99 mole $\%$ ) in the distillate stream from a 3 mole\% acetone waste stream using batch distillation. The device which is used in this work has eight trays that will act as the stages of the batch distillation. The effects of varying reflux ratio and heat load (power) on acetone concentration were studied. Moreover, the operating conditions for the bath distillation column such as flooding and weeping with the extreme limits of operation were considered. The temperatures were also be recorded at each tray. The McCabe-Thiele method was used to determine the theoretical number of trays and compared with actual trays (column efficiency). For a chemical analysis of acetone/water compositions a refractometer was used for a chemical analysis, known acetone/water concentrations were analysed and used to construct a calibration curve. The results obtained showed that, the acetone concentration increases with increasing reflux ratio until a highest concentration was reached. Then, the concentration gradually decreases with increasing reflux ratio. However, the distillate stream with 99 mole \% acetone was achieved at a reflux ratio of $\mathrm{R}=3$ and at both powers $0.5 \mathrm{kw}$ and $0.7 \mathrm{kw}$. Finally, the highest overall column efficiency reached by this work was about $75 \%$.
\end{abstract}

Keywords: Acetone concentration, Batch distillation, Reflux ratio, Flooding, Weeping, Refractometer, Overall column efficiency.

\section{Introduction}

Distillation columns are widely used for separations in industry, most notably in petroleum, natural gas, food processing, perfumery and medicinal and chemical processing. Laboratory scale distillation column are needed to provide adequate practical training for student engineering and plant operators in safe environment. They may also be used to acquire process separation data, of use in full-scale plant design. Distillation is a physical separation process that uses variations in the volatility between compounds in a liquid mixture. The binary distillation separates two components from each other. All liquids have some degree of volatility and this is a measure of their tendency to evaporate. Under the same conditions, a higher volatile compound for example acetone will evaporate faster than water. Boiling the two components would make the difference more obvious, as the less volatile water will boil at a higher temperature than the acetone. More importantly, even when two components are 
mixed, the unique physical properties of the individual component still cause the more volatile component to evaporate faster. This is what makes distillation possible at all. (Mujtaba, 2004).

Batch distillation is a special case of distillation. Figure 3 shows a photo of the batch distillation column that used in this study, where the feed actually comes from the reboiler tank. The top of the column is the same as the enriching section for a fractional distillation system. Also, there is no stripping section for our column in this case. Entrainment takes place in a batch distillation column when the high vapor flowrate. Some of liquid to go through the perforations in the higher tray from the lower tray, thereby causing low separation performance. Flooding happens at very high velocity of liquid and vapor. Also, weeping occurs when the small amount of liquid traveling downward in the column through the tray perforations, where the vapor should be coming up through. Moreover, weeping is dumping, in which a large amount of liquid flows through the tray perforations, instead of the down comers. This liquid has not been contacted with the rising vapor, thus dumping affects the separation performance. It is noticed from Figure (1) a high vapor velocity coupled with a high flow parameter leads to flooding in a distillation column. The flow parameter represents a ratio of liquid to vapor kinetic energies (Fair, 1987).

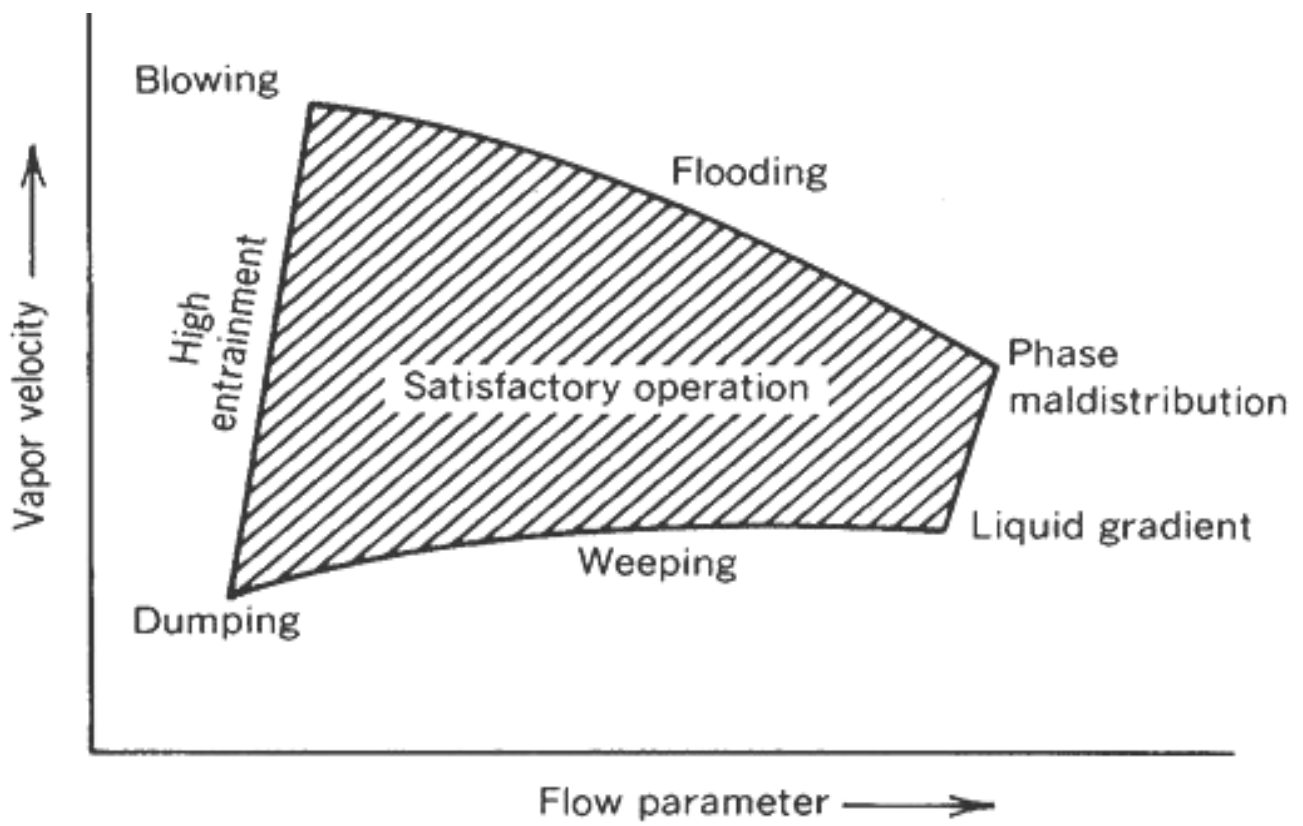

Figure (1): Performance Diagram for Tray Columns (Fair, 1987).

The main objective of this work is to separate the acetone from water using batch distillation. In order to achieve this goal, the effect of changing of reflux ratio and reboiler power (heat load) on the concentration of acetone are studied. Operating conditions of the distillation column such as flooding and weeping are determined. Column efficiency is also estimated. 
The refractive index (R.I) of the acetone/water mixture solution is measured by using Rerfractometer.

\section{Experimental Work}

This section focuses on the laboratory experimental used in this work. The steps of the experiment were fully explained to separate the acetone from water and the maximum percentage obtained is $99 \%$.

\section{Apparatus}

\section{Refractometer}

The refractive index has a large number of applications. It is mostly applied to identify a particular substance, confirm its purity, or measure its concentration. It is generally used to measure the concentration of solute in an aqueous solution (Hirschfelder et al., 1955). Rerfractometer (shown in Figure (2)) was used to measure the refractive index (RI) of the acetone/water mixture solution.

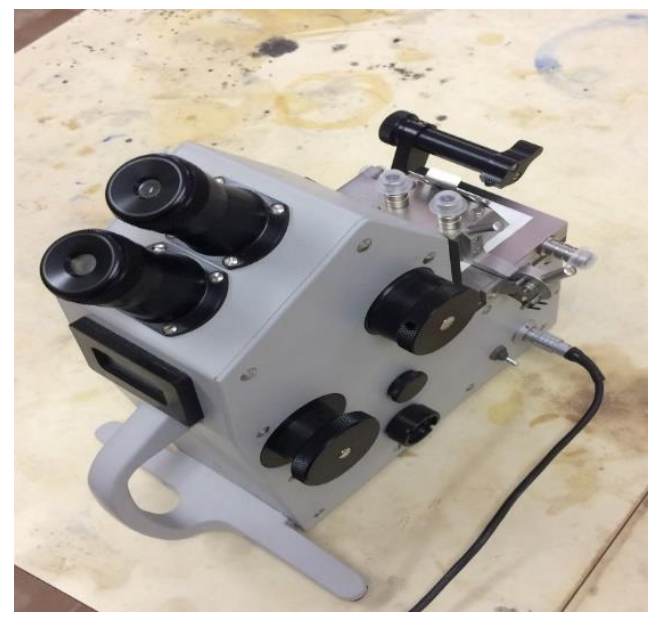

Figure (2): Refractometer.

\section{Batch Distillation Column}

The experimental work has been carried out in batch with sieve plates column $50 \mathrm{~mm}$ internal diameter. A photo of the equipment is included below in Figure (3). The column is insulated to minimize heat loss. The glass column incorporates a total of eight sieve plates in two sections each containing four plates. The first and fifth plates in the column sections are not insulated so that observation of the sieve plates is possible. 


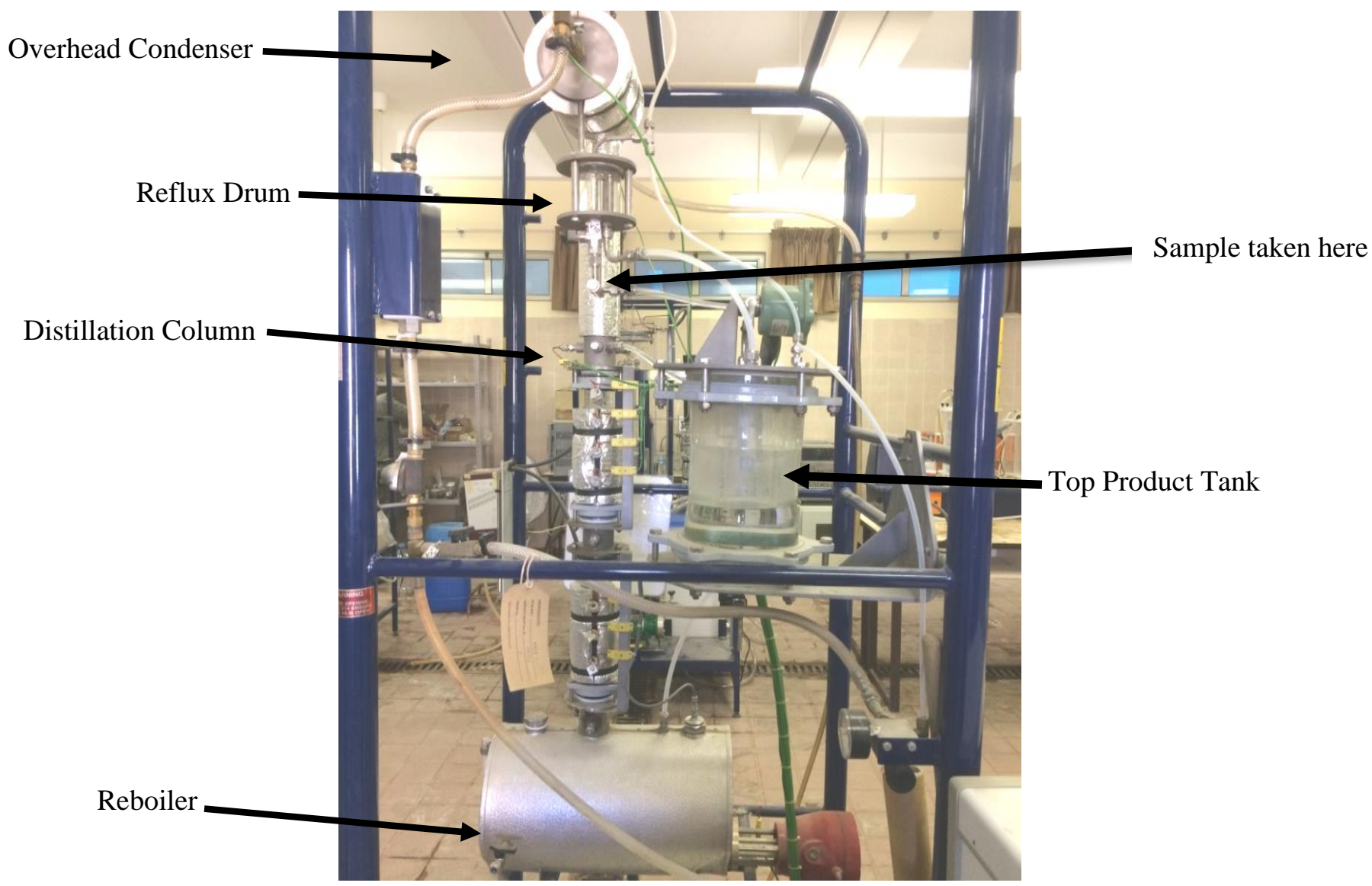

Figure (3): Batch distillation column.

\section{Procedures}

\section{Determining Mixture Compositions}

The acetone-water mixture samples were prepared by mixing several concentration of acetone ranging from $0 \%$ to $100 \%$ in distilled water. A thin layer of the sample was placed between the main prism in the refractometer and the refractive index was measured. Similarly, many samples of acetone (mole\%) were prepared with aqueous solution and the refractive measurements of the samples were recorded. To avoid any error, three readings were taken and then the mean of them were calculated. The results are presented in Table (1).

To find out the percentages of the samples, many samples of acetone-water mixture solution were prepared from 0 to 100 mole percentage. A 10 grams total solution of acetone-water mixture is prepared by dissolving $\left(\mathrm{m}_{1}, \mathrm{gm}\right)$ acetone in $\left(\mathrm{m}_{2}, \mathrm{gm}\right)$ water. In this case the mole percentage of acetone and total weight of solution are known, and the weight of acetone and water are unknown. However, equation 1 was used to find the weights of water and acetone 
for each sample. For example, when $90 \%$ of acetone; the acetone sample weight was 9.67 grams, and the rest of the sample considered water.

Where:

- $\mathrm{m}_{1}+\mathrm{m}_{2}=10 \mathrm{gm}$.

- $\mathrm{m}_{1} \quad=$ Wight of acetone

- $\mathrm{m}_{2} \quad=$ Wight of water

- $58.08=$ Molecular weight of acetone $(\mathrm{gm} / \mathrm{mole})$

- $18=$ Molecular weight of water $(\mathrm{gm} / \mathrm{mole})$

\section{Equipment Set Up}

In this study the power of the reboiler has been selected. The minimum reboiler power was set to $0.5 \mathrm{kw}$, as a very low reboiler power will lead to a long production time and weeping, which are commercially undesirable. Also, the reboiler load limit was set to $1 \mathrm{~kW}$, where a reliably high reboiler power will cause a flood in the column, reducing the concentration of acetone in the distillation product.

Minimum reflux Ratio, $\mathrm{R}_{\min }$ was also determined. First, the enriching line for minimum reflux was drawn and its slope was determined Figure (9). With this value, $\mathrm{R}_{\min }$ was determined to be about 1.8. The optimal $\mathrm{R}$ should be approximately 1.2 to 1.5 times $\mathrm{R}_{\min }$, which is equivalent in this work to 2.16 to 2.7 . However, high reflux ratios are not commercially desirable due to high heating and cooling costs (Mujtaba, 2004). Thus, the maximum reflux ratio for this experiment was set at 7 , which was higher than the optimal theoretical reflux ratio.

\section{Feed Solution Preparation}

In this work the feed solution is 10 litres of mixture of 3 mole $\%$ acetone and 97 mole \% water:

$$
\begin{gathered}
\frac{\text { Acetone mole } \% \times \text { M.wt of acetone }}{\text { Density of acetone }}: \frac{\text { Water mole } \% \times \text { M.wt of water }}{\text { Density of water }} \\
(3 \times 58.08) / 0.790:(97 \times 18) / 1
\end{gathered}
$$$$
220.25: 1746
$$

$$
1: 7.93
$$

Thus for 10 litres there are 1.12 litres of acetone and 8.88 litres of freshwater. 


\section{Experimental Runs}

- Set the device to operate at the total reflux. Make sure that all valves on the equipment are closed. Open the valve on the reflux tube. Load a 10-liter of feed mixture directly into the reboiler.

- Open the valve of the condenser until the cooling water flow rate reaches the overhead condenser about (2.5 - 3) liters / min

- Turn on the power on the control panel on the digital watt scale. The reboiler content will start to be heated and can be seen on the temperatures reading scale.

- Open the valves connecting the base and the top of the column. At the beginning of the experiment there will be no pressure difference in the distillation column.

- When the product appears in the reflux drum, operate the device at total reflux (100\% return rate). The vapor will start to rise up in the distillation column. Leave the apparatus at total reflux for 15 to 20 minutes. The system will be in equilibrium condition when the temperatures (from T1 to T8) are approximately constant with time.

- Set the reflux ratio for example reflux ratio $\mathrm{R}=3$ at intervals of 10 minutes, record all temperatures and collect a sample from the top product tank and measure the refractive index of each sample.

- After taking the samples, take readings of tray temperatures (T1 to T8 and T9 reboiler temp) and pressure drop over both (top) and the (bottom) sections by the manometer.

- Leave 5 to 10 minutes between each measurements before starting the next set until the system reaches equilibrium again.

\section{Results and Discussion}

\section{Refractive Index of Acetone-Water Mixture at Different Concentrations}

Refractive index of acetone/ water mixtures solution were measured at room temperature (about $25 \mathrm{C}^{\circ}$ ) with acetone concentration ranging from 0 to $100 \%$ by mole. The results are tabulated in the Table (1).

Table (1): Refractive Index. VS. Mole \% of Acetone.

\begin{tabular}{|c|c|c|c|c|}
\hline No. sample & $\begin{array}{c}\text { Acetone } \\
\mathbf{m}_{\mathbf{1}}, \mathbf{g}\end{array}$ & $\begin{array}{c}\text { Water } \\
\mathbf{m}_{\mathbf{2}}, \mathbf{g}\end{array}$ & $\begin{array}{c}\text { Acetone } \\
\text { mole \% }\end{array}$ & R.I \\
\hline 1 & 0 & 10 & 0 & 1.33303 \\
\hline 2 & 1.45 & 8.55 & 5 & 1.34411 \\
\hline 3 & 2.64 & 7.36 & 10 & 1.35214 \\
\hline 4 & 3.63 & 6.37 & 15 & 1.35616 \\
\hline 5 & 4.47 & 5.53 & 20 & 1.36119 \\
\hline
\end{tabular}




\begin{tabular}{|c|c|c|c|c|}
\hline 6 & 5.18 & 4.82 & 25 & 1.36322 \\
\hline 7 & 5.8 & 4.2 & 30 & 1.36526 \\
\hline 8 & 6.35 & 3.65 & 35 & 1.36522 \\
\hline 9 & 6.83 & 3.17 & 40 & 1.36622 \\
\hline 10 & 7.25 & 2.75 & 45 & 1.36726 \\
\hline 11 & 7.63 & 2.37 & 50 & 1.36622 \\
\hline 12 & 7.98 & 2.02 & 55 & 1.36622 \\
\hline 13 & 8.29 & 1.71 & 60 & 1.36522 \\
\hline 14 & 8.57 & 1.43 & 65 & 1.36422 \\
\hline 15 & 8.83 & 1.17 & 70 & 1.36422 \\
\hline 16 & 9.06 & 0.94 & 75 & 1.36322 \\
\hline 17 & 9.28 & 0.72 & 80 & 1.3622 \\
\hline 18 & 9.48 & 0.52 & 85 & 1.3615 \\
\hline 19 & 9.67 & 0.33 & 90 & 1.3612 \\
\hline 20 & 9.84 & 0.16 & 95 & 1.36019 \\
\hline 21 & 10 & 0 & 100 & 1.35917 \\
\hline & & & & \\
\hline
\end{tabular}

Figure (4) is drawn between acetone concentration and refractive index. It is clear from the figure that the relationship of the refractive index and acetone concentration is linear up to a certain concentration (about 45\%) and then the refractive index decreases with increasing acetone concentration.

This observation maybe due to, In the binary system such as acetone and water, dependent on the number of particles present and the radius size, the different molecules can be roughly packed or less. When the acetone molecule dissolves in water, because of the formation of the hydrogen bond between the various molecules, it causes an increase in the shrinkage of the volume size as the change resulting from the close packing of water and acetone is larger than normal forces of repulsion. When the close packing is maximum, the areas between the particles are minimized; therefore, the volume is reduced to the maximum (Mukeshet al., 2017). 


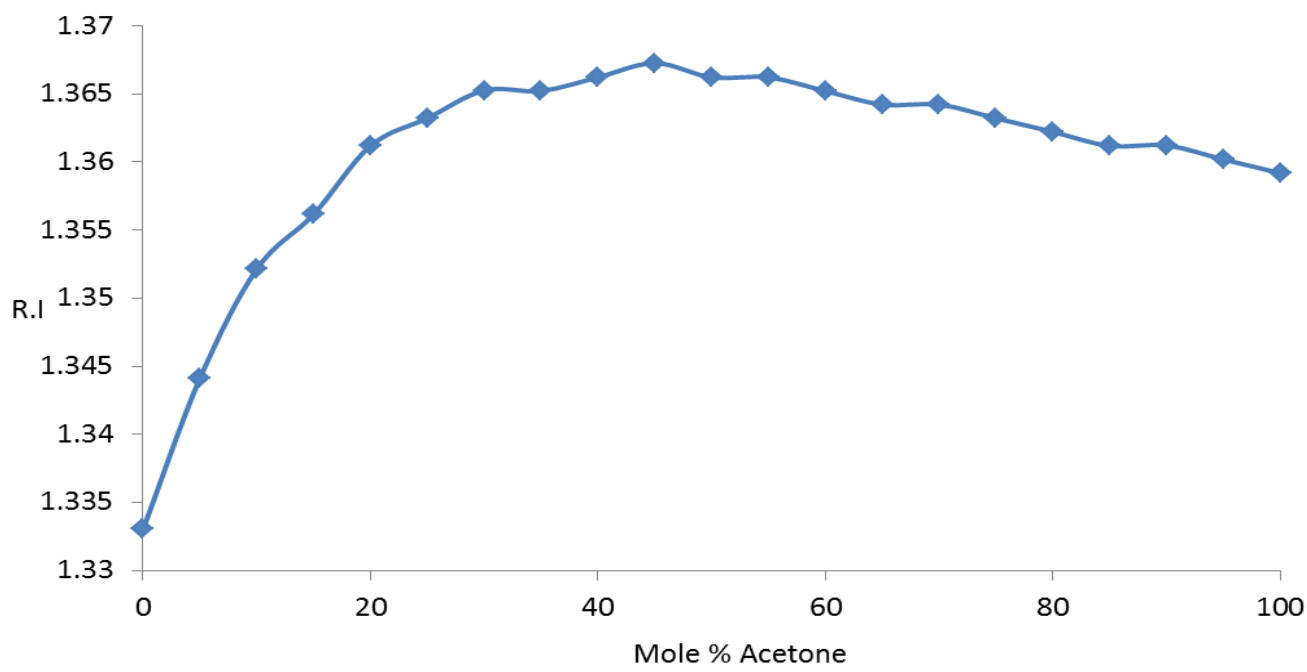

Figure 4 Calibration Curve of Refractive Index (R.I). VS. Concentration of Acetone (Mole\%).

\section{Outline of Experimental Runs}

The calibration curve Figure (4) of the refractive index is parabolic, at a certain refractive index, it is likely to obtain two values for concentration of acetone mole in the same RI reading. Therefore, to determine which of the two values is the exact value, the T-xy scheme for acetone / water is used in Figure (5). The upper temperature reading (T1) of the batch column (as shown in the tables in Appendix A) was used to decide which concentration is probably the right one.

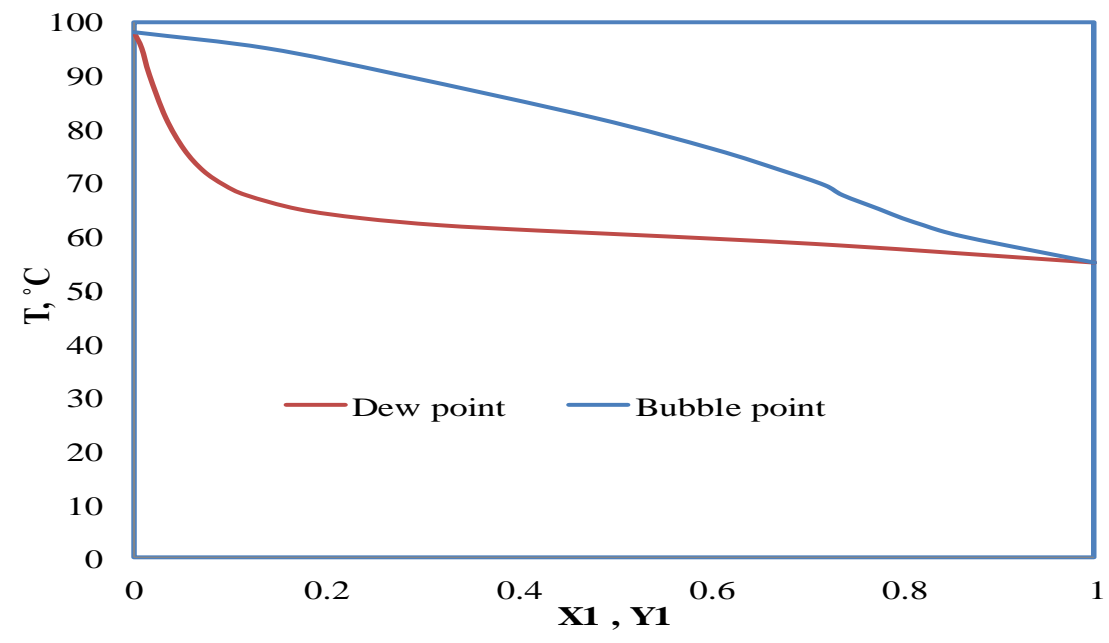

Figure (5): T-XY Diagram for Acetone/Water at Latm. 


\section{Effect of Changing Reflux Ratio on Acetone Concentration}

Figure 6 demonstrates, the effect of variation reflux ratio on acetone mole concentration at different reboiler powers. It is interesting to reflect that when the reflux ratio is increased the acetone concentration is increased up to reflux ratio $\mathrm{R}=3$ then after the concentration of acetone in the distillate product gradually decreases as the reflux ratio increases for all powers. This observation maybe due to too much liquid being refluxed into the column. This might possibly cause flooding if the vapor flow rate is high or even weeping if the vapor velocity was low. However, the optimum and highest concentration of acetone (99 mole\%) was achieved at $\mathrm{R}=3$ at both powers $0.5 \mathrm{kw}$ and $0.7 \mathrm{kw}$.

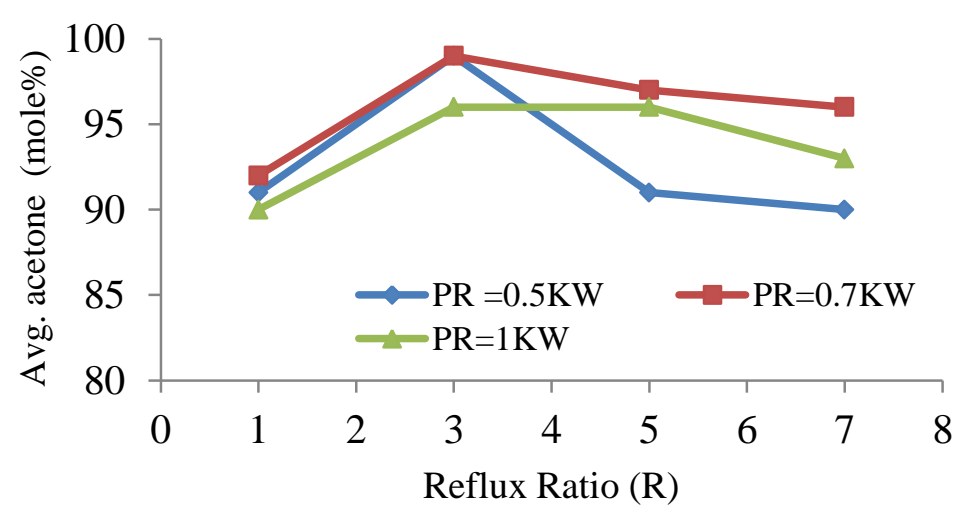

Figure (6): Acetone Concentration Mole\%. VS. Reflux Ratio.

\section{Effect of Changing Reboiler Power on Acetone Concentration}

Figure (7) illustrates, the influence of changing reboiler power on acetone concentration at different reflux ratios. As can be seen in Figure (7), the power is increased, the acetone concentration is increased up to power $=0.7 \mathrm{kw}$, thereafter the acetone concentration actually decreased. However, the highest concentrations of acetone was achieved at power $=0.7 \mathrm{kw}$. High reboiler power may caused high vapour flow rate into the column, which usually led to flooding conditions in the column. This caused a decrease in acetone concentration in the distillate. 


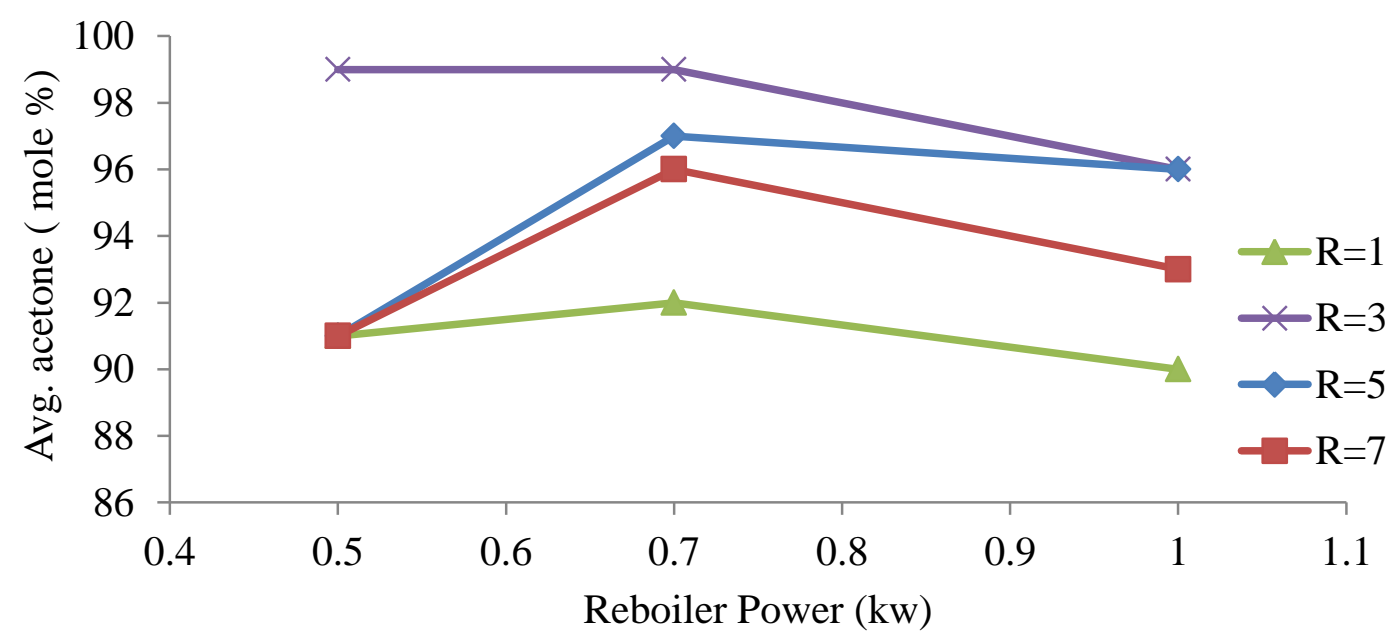

Figure (7) Acetone Concentration Mole\% .VS. Power Reboiler.

\section{Effect Reboiler Power on Pressure Drop in a Column}

Figure 8 shows the relationship between the pressure drop over both (top) and the (bottom) sections of the column and reboiler power at different reflux ratios. A high reboiler power caused high vapor flow rate into the column and vapor velocity, which normally let to increasing in pressure drop in a column. Also, thus, a high reflux ratio together with a high reboiler power will possibly lead to entrainment flooding conditions in the batch distillation.

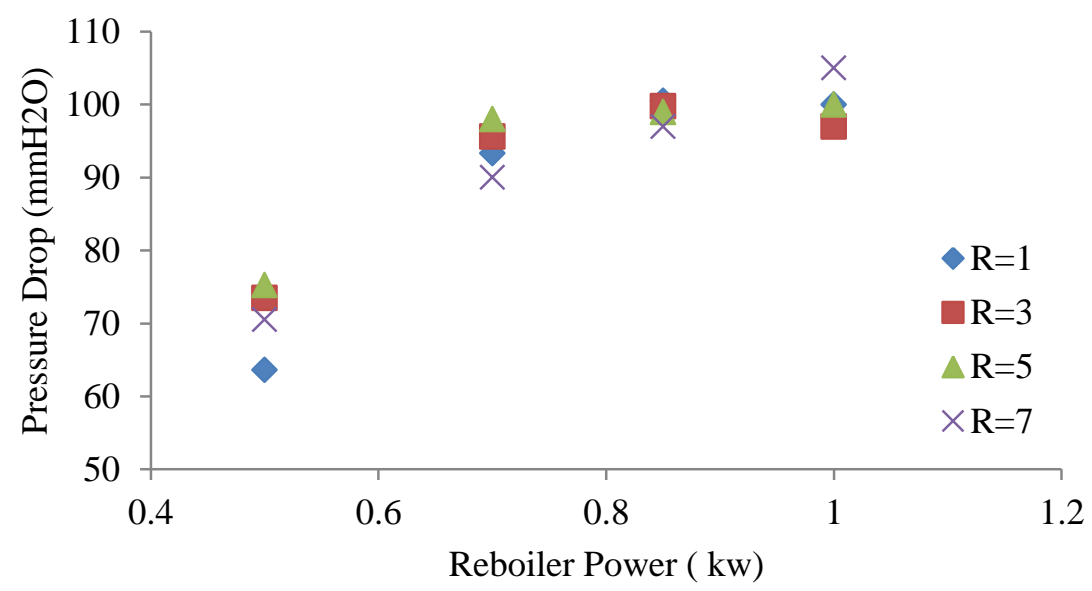

Figure (8): Pressure Drop.vs. Reboiler Power.

\section{Column Efficiency}

The McCabe-Thiele diagram was determined and the number of theoretical number of trays was calculated for each run. An example is shown below. However, in this method contains 
the reboiler as a theoretical stage (Geankopolis, 2003). Only the stages in the column should be taken to find out the overall column efficiency, this fact was considered in this work. Also, the reflux ratio should be above the $\mathrm{R}_{\min }$. On the other hand, the higher the number of plates, the lower $\mathrm{R}$ values and this condition is reached manually by drawing in the McCabe-Thiele Figure (9). The optimal reflux ratio should be between 1.2 to 1.5 times $\mathrm{R}_{\min }$ (Geankopolis, 2003). In this experiment was set at $\mathrm{R}=7$ as maximum reflux ration, which was already higher than the theoretical optimal $\mathrm{R}$. Total feed of acetone mole concentration in all experimental is 3 mole $\%$. By comparing the actual number of trays to the theoretical in table 2, it can be noted that this column used was not vary efficient, the same degree of separation can be reached with less trays. This has been confirmed by the overall efficiency values of the column $\left(\mathrm{E}_{0} \%\right)$. However, the maximum value for the overall efficiency achieved was $75 \%$, while the minimum value was $25 \%$.

- Hand Calculation For Run 6 at product acetone $=99$ mole $\%$

$\therefore \quad \mathrm{X}_{\mathrm{B}}=$ mole fraction of feed acetone $=0.03$

$\mathrm{X}_{\mathrm{D}}=$ mole fraction of acetone at top product $=0.99$

Note, the $X_{B}$ is constant for all Runs

Slope of enriching line from figure $9=0.646$

Slope $=\frac{R \min }{R \min +1}=0.646$ by solve this equation $\mathrm{R}_{\min }=1.8$.

From figure 9 below, $\mathrm{N}_{\text {th }} \approx 7$ stages.

$\mathrm{N}_{\text {act }}=$ The actual number of trays are 8 stages

Efficiency $\left(\mathrm{E}_{0} \%\right)=\left[\mathrm{N}_{\text {th }} / \mathrm{N}_{\text {act }}\right] \times 100=[(7-1) / 8] \times 100=75 \%$ 


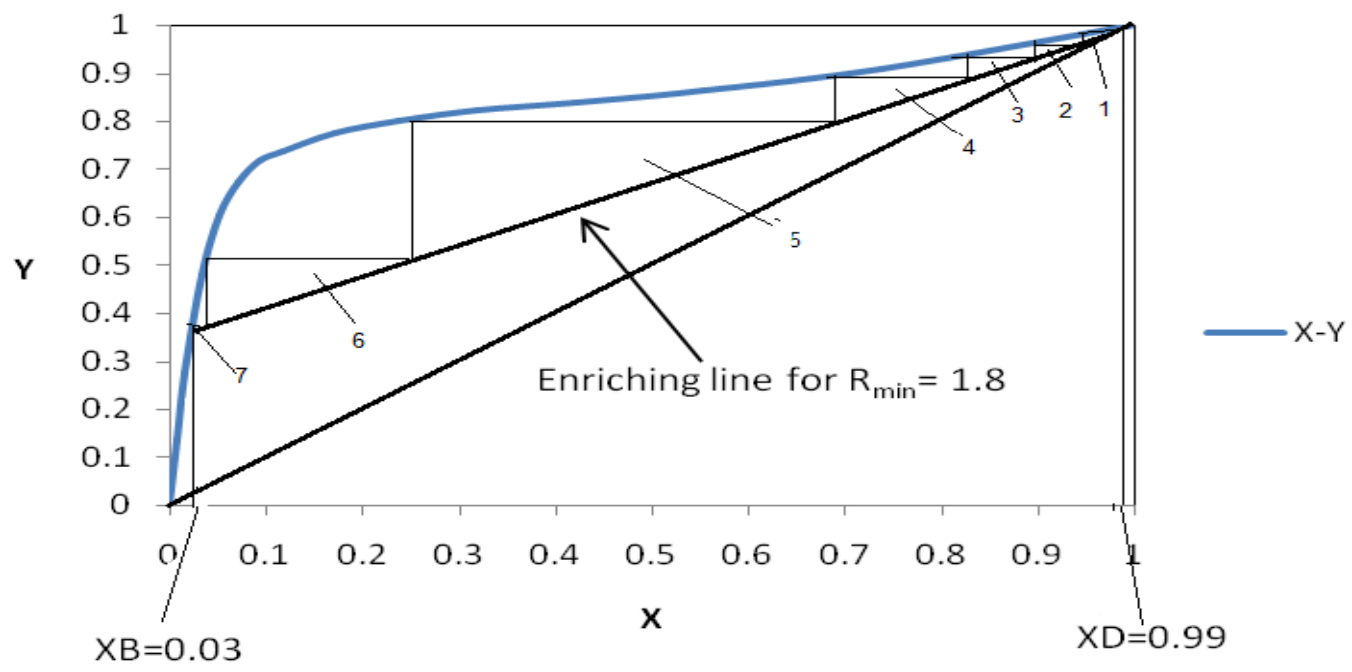

Figure (9): Determination of $R_{\min }$ and $\mathbf{N}_{\mathrm{th}}$ for Run 6.

Table (2): Runs Results Hand Calculation for $\mathbf{N}_{\text {th }}, \mathbf{E}_{0} \& \mathbf{R}_{\min }$.

\begin{tabular}{|c|c|c|c|}
\hline Run & $\mathbf{R}_{\min }$ & $\mathbf{N}_{\text {th }}$ & $\mathbf{E}_{\mathbf{0}} \%$ \\
\hline 1 & 1.62 & 3.5 & 31.25 \\
\hline 2 & 1.8 & 6.5 & 75 \\
\hline 3 & 1.62 & 3.5 & 31.25 \\
\hline 4 & 1.62 & 3.5 & 31.25 \\
\hline 5 & 1.62 & 3.5 & 31.25 \\
\hline 6 & 1.8 & 6.5 & 75 \\
\hline 7 & 1.76 & 5 & 50 \\
\hline 8 & 1.68 & 4 & 37.5 \\
\hline 9 & 1.55 & 3 & 25 \\
\hline 10 & 1.7 & 4 & 37.5 \\
\hline 11 & 1.68 & 4 & 37.5 \\
\hline 12 & 1.64 & 3.5 & 31.25 \\
\hline
\end{tabular}

\section{Conclusions}

- This study was focused on the feasibility of obtaining maximum mole percentage of acetone in the distillate stream from from a 3 mole\% acetone waste stream using batch distillation. The apparatus has eight trays that will act as the stages of the batch 
distillation. The refractometer was selected as a method for measuring the concentration of acetone / water samples.

- The calibration curve of Refractive Index of acetone/water solution showed that approximately linear relationship between RI and concentration of acetone up to a certain concentration of acetone then refractive index decreased with increased in concentration of acetone.

- The acetone concentration in the overhead product increased with increasing reflux ratio up to a reflux ratio of $\mathrm{R}=3$ at most powers. Then, a gradual decrease in acetone concentration with increase in reflux ratio over 3 .

- The optimum and highest acetone mole concentration in the overhead product was achieved about $99 \mathrm{~mol} \%$ at $\mathrm{R}=3$ and at reboiler powers $=0.5 \mathrm{~kW}$ and $0.7 \mathrm{~kW}$.

- The highest number of theoretical plates obtained was found 7 plates and the efficiency of the distillation column was $75 \%$ at the highest concentration of acetone.

\section{References}

- Mujtabta, I. M. (2004), Batch Distillation Design And Operation Series On Chemical Engineering, Volume 3.

- Fair, J. (1987) “Distillation” Handbook of Separation Process Technology. Rousseau, R. USA: Wiley-Interscience,. Pages 229-339.

- Hirschfelder, J. O., Curtiss, C. F. and Bird R. B., (1954), Molecular Theory of Gases and Liquids, Wiley, New York, 1954.doi 10.1002/pol.1955.120178311.

- Mukesh Upadhyay et al., (2017) American International Journal of Research in Science, Technology, Engineering \& Mathematics, 20(1), September-November, 2017, pp. 77-79.

- Geankopolis, C.J. (2003), Transport Processes and Separation Process Principles. USA: Prentice Hall. 


\section{Appendix A: Raw Data from Distillation Runs.}

Table (A.1): Run 1 at Power 0.5KW, R=1.

\begin{tabular}{|c|c|c|c|c|c|c|c|c|c|c|c|}
\hline Time,min & $\mathbf{T}_{\mathbf{1}} / \mathbf{c}^{\mathbf{0}}$ & $\mathbf{T}_{2} / \mathbf{c}^{\mathbf{0}}$ & $\mathbf{T}_{\mathbf{3}} / \mathbf{c}^{\mathbf{0}}$ & $\mathbf{T}_{\mathbf{4}} / \mathbf{c}^{\mathbf{0}}$ & $\mathbf{T}_{5} / \mathbf{c}^{\mathbf{0}}$ & $\mathbf{T}_{\mathbf{6}} / \mathbf{c}^{\mathbf{0}}$ & $\mathbf{T}_{7} / \mathbf{c}^{\mathbf{0}}$ & $\mathbf{T}_{\mathbf{8}} / \mathbf{c}^{\mathbf{0}}$ & $\mathbf{T}_{\mathbf{9}} / \mathbf{c}^{\mathbf{0}}$ & $\Delta \mathbf{P}_{\mathbf{m m H 2 O}}$ & $\mathbf{R . I}$ \\
\hline 0 & 39 & 40 & 47 & 55.7 & 55.8 & 57 & 57.8 & 68.5 & 93.5 & - & - \\
\hline 10 & 54.5 & 53.5 & 54.2 & 57 & 67 & 86 & 89 & 91 & 95 & - & - \\
\hline 20 & 55.3 & 54.2 & 54.9 & 56.3 & 55.1 & 56.6 & 57 & 62 & 96 & - & - \\
\hline 25 & 55.4 & 55 & 55.1 & 56.3 & 56 & 56.6 & 57.3 & 64.2 & 96 & - & - \\
\hline $30, \mathrm{R}$ & 55.6 & 54.3 & 55 & 56.7 & 56.6 & 58.1 & 60.6 & 84.5 & 96.4 & 65 & 1.36019 \\
\hline 35 & 56.4 & 56 & 56.6 & 60 & 74 & 92 & 94 & 95 & 97 & 73 & 1.36019 \\
\hline 40 & 57 & 65.2 & 73.1 & 89.9 & 93.4 & 95 & 94.3 & 96 & 97 & 6 & 1.36130 \\
\hline 45 & - & - & - & - & - & - & - & 98 & 98 & 74 & 1.3614 \\
\hline
\end{tabular}

Table (A.2): Run 2 at Power 0.5KW, R=3.

\begin{tabular}{|c|c|c|c|c|c|c|c|c|c|c|c|}
\hline $\begin{array}{l}\text { Time, } \\
\text { Min }\end{array}$ & $\begin{array}{c}\mathbf{T}_{1} / \mathbf{c} \\
\mathbf{0}\end{array}$ & $\begin{array}{c}\mathbf{T}_{2} / \mathbf{c} \\
\mathbf{0}\end{array}$ & $\begin{array}{c}\mathbf{T}_{3} / \mathbf{c} \\
\mathbf{0}\end{array}$ & $\begin{array}{c}\mathbf{T}_{4} / \mathbf{c} \\
\mathbf{0}\end{array}$ & $\begin{array}{c}\mathbf{T}_{5} / \mathrm{c} \\
\mathbf{0}\end{array}$ & $\begin{array}{c}\mathbf{T}_{6} / \mathbf{c} \\
\mathbf{0}\end{array}$ & $\begin{array}{c}\mathbf{T}_{7} / \mathbf{c} \\
\mathbf{0}\end{array}$ & $\begin{array}{c}\mathbf{T}_{8} / \mathbf{c} \\
\mathbf{0}\end{array}$ & $\begin{array}{c}\mathbf{T}_{9} / \mathrm{c} \\
\mathbf{0}\end{array}$ & $\begin{array}{c}\Delta \mathbf{P}_{\mathrm{mmH} 2} \\
\mathrm{o}\end{array}$ & R.I \\
\hline 0 & 54.8 & 54.4 & 55 & 56.7 & 59.1 & 70.7 & 86.3 & 90.8 & 94 & - & - \\
\hline 10 & 55.1 & 54.1 & 54.2 & 55.6 & 55 & 55.8 & 56 & 91.3 & 94.7 & - & - \\
\hline $15, \mathrm{R}$ & 55.4 & 54.6 & 54.8 & 56.1 & 55.8 & 56.2 & 57.3 & 93.4 & 94.7 & 65 & 1.35919 \\
\hline 20 & 55.6 & 55.1 & 55.7 & 58.2 & 69.3 & 89.5 & 91.3 & 93.2 & 95.1 & 67 & 1.35919 \\
\hline 25 & 57 & 58.8 & 58.3 & 72.1 & 84 & 91.9 & 91.6 & 93.3 & 95.6 & 58 & 1.35919 \\
\hline 30 & 59.1 & 74.1 & 84 & 88 & 90.3 & 92.9 & 92.3 & 93.7 & 96 & 65 & 1.35919 \\
\hline
\end{tabular}

Table (A.3): Run 3 at Power 0.5KW, R=5.

\begin{tabular}{|c|c|c|c|c|c|c|c|c|c|c|c|}
\hline Time,min & $\mathbf{T}_{\mathbf{1}} / \mathbf{c}^{\mathbf{0}}$ & $\mathbf{T}_{2} / \mathbf{c}^{\mathbf{0}}$ & $\mathbf{T}_{\mathbf{3}} / \mathbf{c}^{\mathbf{0}}$ & $\mathbf{T}_{4} / \mathbf{c}^{\mathbf{0}}$ & $\mathbf{T}_{5} / \mathbf{c}^{\mathbf{0}}$ & $\mathbf{T}_{6} / \mathbf{c}^{\mathbf{0}}$ & $\mathbf{T}_{7} / \mathbf{c}^{\mathbf{0}}$ & $\mathbf{T}_{\mathbf{8}} / \mathbf{c}^{\mathbf{0}}$ & $\mathbf{T}_{\mathbf{9}} / \mathbf{c}^{\mathbf{0}}$ & $\Delta \mathbf{P}_{\mathbf{m m H 2 0}}$ & $\mathbf{R . I}$ \\
\hline 0 & 56.6 & 56.7 & 56.5 & 60.2 & 66.9 & 78.8 & 90.3 & 94.6 & 96.4 & - & - \\
\hline 10 & 55 & 52.3 & 51.3 & 55.4 & 55.1 & 56.5 & 59.1 & 83.7 & 97.7 & - & - \\
\hline R15 & 70.2 & 70.4 & 69.1 & 70.2 & 70.4 & 70.5 & 69.9 & 72.2 & 98 & 65 & 1.36019 \\
\hline 25 & 59.2 & 64.3 & 88.7 & 96.5 & 96.7 & 97 & 97 & 97.8 & 98.4 & 75 & 1.3612 \\
\hline 30 & - & - & - & - & - & - & - & - & 99.6 & 76 & 1.3612 \\
\hline 35 & - & - & - & - & - & - & - & - & 99.9 & 85 & 1.3612 \\
\hline
\end{tabular}

Table (A.4): Run 4 at Power 0.5KW, $R=7$.

\begin{tabular}{|c|c|c|c|c|c|c|c|c|c|c|c|}
\hline Time,min & $\mathbf{T}_{\mathbf{1}} / \mathbf{c}^{\mathbf{0}}$ & $\mathbf{T}_{2} / \mathbf{c}^{\mathbf{0}}$ & $\mathbf{T}_{\mathbf{3}} / \mathbf{c}^{\mathbf{0}}$ & $\mathbf{T}_{\mathbf{4}} / \mathbf{c}^{\mathbf{0}}$ & $\mathbf{T}_{5} / \mathbf{c}^{\mathbf{0}}$ & $\mathbf{T}_{6} / \mathbf{c}^{\mathbf{0}}$ & $\mathbf{T}_{7} / \mathbf{c}^{\mathbf{0}}$ & $\mathbf{T}_{\mathbf{8}} / \mathbf{c}^{\mathbf{0}}$ & $\mathbf{T}_{\mathbf{9}} / \mathbf{c}^{\mathbf{0}}$ & $\Delta \mathbf{P}_{\mathbf{m m H 2 O}}$ & $\mathbf{R . I}$ \\
\hline 0 & 55.8 & 55.3 & 55.5 & 56.7 & 56.6 & 57.6 & 58.8 & 72.3 & 93.9 & - & - \\
\hline 10 & 55.7 & 55 & 55.2 & 56.4 & 56 & 56.5 & 57.1 & 62.5 & 94.9 & - & - \\
\hline 20 & 55.9 & 54.9 & 55 & 56.2 & 55.5 & 56.2 & 56.8 & 62 & 94.8 & & \\
\hline $25, \mathrm{R}$ & 55.7 & 54.9 & 55.1 & 56.3 & 56 & 56.6 & 57.7 & 65.5 & 95.2 & 66 & 1.36130 \\
\hline
\end{tabular}




\begin{tabular}{|l|c|c|c|c|c|c|c|c|c|c|c|}
\hline 30 & 55.6 & 54.9 & 55.2 & 56.3 & 56.1 & 57 & 58.7 & 69.3 & 95.7 & 66 & 1.36019 \\
\hline 35 & 55.7 & 54.9 & 55.1 & 56.4 & 56.3 & 57.3 & 59.3 & 85.4 & 96.4 & 69 & 1.36019 \\
\hline 40 & 55.9 & 55.4 & 56.3 & 59.6 & 71.7 & 92.7 & 94.3 & 96 & 96.9 & 77 & 1.36019 \\
\hline 45 & 55.9 & 55.4 & 56.4 & 60.4 & 76.6 & 93.8 & 95 & 96.6 & 97.5 & 75 & 1.36130 \\
\hline
\end{tabular}

Table (A.5): Run 5 at Power 0.7KW, $R=1$.

\begin{tabular}{|c|c|c|c|c|c|c|c|c|c|c|c|}
\hline Time,min & $\mathbf{T}_{1} / \mathbf{c}^{\mathbf{0}}$ & $\mathbf{T}_{2} / \mathbf{c}^{\mathbf{0}}$ & $\mathbf{T}_{\mathbf{3}} / \mathbf{c}^{\mathbf{0}}$ & $\mathbf{T}_{4} / \mathbf{c}^{\mathbf{0}}$ & $\mathbf{T}_{5} / \mathbf{c}^{\mathbf{0}}$ & $\mathbf{T}_{\mathbf{6}} / \mathbf{c}^{\mathbf{0}}$ & $\mathbf{T}_{7} / \mathbf{c}^{\mathbf{0}}$ & $\mathbf{T}_{8} / \mathbf{c}^{\mathbf{0}}$ & $\mathbf{T}_{\mathbf{9}} / \mathbf{c}^{\mathbf{0}}$ & $\Delta \mathbf{P}_{\mathbf{m m H 2 O}}$ & $\mathbf{R . I}$ \\
\hline 0 & 55.5 & 54.8 & 55.2 & 56.5 & 58.6 & 54.6 & 55 & 57.5 & 85 & - & - \\
\hline 10 & 55.5 & 54.8 & 55 & 56 & 55.4 & 55.7 & 55.7 & 58.3 & 85.1 & - & - \\
\hline, $\mathrm{R} 20$ & 56 & 55.7 & 56.6 & 59.2 & 63 & 77 & 82.2 & 84.8 & 88 & 94 & 1.36019 \\
\hline 30 & - & - & - & - & - & - & - & - & 90.7 & 88 & 1.3612 \\
\hline 40 & - & - & - & - & - & - & - & - & 93.2 & 98 & 1.3612 \\
\hline
\end{tabular}

Table (A.6): Run 6 at Power 0.7KW, R =3.

\begin{tabular}{|c|c|c|c|c|c|c|c|c|c|c|c|}
\hline Time,min & $\mathbf{T}_{\mathbf{1}} / \mathbf{c}^{\mathbf{0}}$ & $\mathbf{T}_{2} / \mathbf{c}^{\mathbf{0}}$ & $\mathbf{T}_{3} / \mathbf{c}^{\mathbf{0}}$ & $\mathbf{T}_{\mathbf{4}} / \mathbf{c}^{\mathbf{0}}$ & $\mathbf{T}_{5} / \mathbf{c}^{\mathbf{0}}$ & $\mathbf{T}_{\mathbf{6}} / \mathbf{c}^{\mathbf{0}}$ & $\mathbf{T}_{7} / \mathbf{c}^{\mathbf{0}}$ & $\mathbf{T}_{\mathbf{8}} / \mathbf{c}^{\mathbf{0}}$ & $\mathbf{T}_{\mathbf{9}} / \mathbf{c}^{\mathbf{0}}$ & $\Delta \mathbf{P}_{\mathbf{m m H 2 O}}$ & $\mathbf{R . I}$ \\
\hline 0 & 41.5 & 41.8 & 43.2 & 44.4 & 50.2 & 51.2 & 54 & 55.8 & 85.7 & - & - \\
\hline 5 & 54 & 54.6 & 53.1 & 53.6 & 52 & 52.4 & 54.2 & 54 & 86.5 & - & - \\
\hline 10 & 58.8 & 56.4 & 55.1 & 56.6 & 56.4 & 53 & 53.1 & 57.4 & 86.8 & - & - \\
\hline $15, \mathrm{R}$ & 55.9 & 55.3 & 56 & 57.7 & 60.2 & 70.2 & 82.2 & 84.1 & 88.1 & 94 & 1.35919 \\
\hline 20 & 55.7 & 55.1 & 55.6 & 57.4 & 58.5 & 64.1 & 80.5 & 86 & 89.9 & 96 & 1.35919 \\
\hline 25 & 55.7 & 55 & 55.4 & 57 & 57.1 & 59.2 & 68.1 & 82.8 & 90.5 & 97 & 1.35919 \\
\hline 30 & 55.6 & 54.9 & 55.2 & 56.6 & 56.3 & 57.5 & 60.2 & 76.6 & 93.3 & 97 & 1.35919 \\
\hline
\end{tabular}

Table (A.7): Run 7 at Power 0.7KW, R=5.

\begin{tabular}{|c|c|c|c|c|c|c|c|c|c|c|c|}
\hline Time,min & $\mathbf{T}_{\mathbf{1}} / \mathbf{c}^{\mathbf{0}}$ & $\mathbf{T}_{2} / \mathbf{c}^{\mathbf{0}}$ & $\mathbf{T}_{3} / \mathbf{c}^{\mathbf{0}}$ & $\mathbf{T}_{\mathbf{4}} / \mathbf{c}^{\mathbf{0}}$ & $\mathbf{T}_{5} / \mathbf{c}^{\mathbf{0}}$ & $\mathbf{T}_{\mathbf{6}} / \mathbf{c}^{\mathbf{0}}$ & $\mathbf{T}_{\mathbf{7}} / \mathbf{c}^{\mathbf{0}}$ & $\mathbf{T}_{\mathbf{8}} / \mathbf{c}^{\mathbf{0}}$ & $\mathbf{T}_{\mathbf{9}} / \mathbf{c}^{\mathbf{0}}$ & $\Delta \mathbf{P}_{\mathbf{m m H 2 O}}$ & $\mathbf{R . I}$ \\
\hline 0 & 56.3 & 55.5 & 56.8 & 57.5 & 57.3 & 58.3 & 59 & 62.9 & 86.9 & - & - \\
\hline 10 & 55.7 & 55 & 55.4 & 56.5 & 55.8 & 56.3 & 56.3 & 59.9 & 87 & - & - \\
\hline $20, \mathrm{R}$ & 56.1 & 55.5 & 56 & 56.9 & 56.9 & 56.9 & 57.3 & 61.4 & 88.1 & 95 & 1.35919 \\
\hline 25 & 56.4 & 55.6 & 56.1 & 57.1 & 57 & 58.2 & 59.9 & 66.1 & 89.7 & 98 & 1.36019 \\
\hline 30 & 56.7 & 56.1 & 56 & 57.1 & 56.9 & 57.4 & 58.3 & 64 & 90.4 & 99 & 1.36019 \\
\hline 35 & 56.7 & 55.7 & 56 & 57.1 & 57 & 57.9 & 59 & 66.8 & 91.7 & 100 & 1.35919 \\
\hline
\end{tabular}

Table (A.8): Run 8 at Power 0.7KW, R=7.

\begin{tabular}{|c|c|c|c|c|c|c|c|c|c|c|c|}
\hline Time,min & $\mathbf{T}_{1} / \mathbf{c}^{\mathbf{0}}$ & $\mathbf{T}_{2} / \mathbf{c}^{\mathbf{0}}$ & $\mathbf{T}_{3} / \mathbf{c}^{\mathbf{0}}$ & $\mathbf{T}_{4} / \mathbf{c}^{\mathbf{0}}$ & $\mathbf{T}_{5} / \mathbf{c}^{\mathbf{0}}$ & $\mathbf{T}_{6} / \mathbf{c}^{\mathbf{0}}$ & $\mathbf{T}_{7} / \mathbf{c}^{\mathbf{0}}$ & $\mathbf{T}_{8} / \mathbf{c}^{\mathbf{0}}$ & $\mathbf{T}_{9} / \mathbf{c}^{\mathbf{0}}$ & $\Delta \mathbf{P}_{\mathbf{m m H} 2}$ & $\mathbf{R . I}$ \\
\hline 0 & 56.9 & 56.5 & 54.1 & 57.7 & 58.3 & 60 & 65.7 & 81.6 & 88.6 & - & - \\
\hline 10 & 57.4 & 55.9 & 56 & 57.7 & 59 & 60.1 & 60.5 & 64.6 & 88.6 & - & - \\
\hline $20, \mathrm{R}$ & 56.6 & 55.4 & 55.9 & 57.1 & 56.8 & 57 & 57 & 60.5 & 88.6 & 100 & 1.36019 \\
\hline
\end{tabular}




\begin{tabular}{|c|c|c|c|c|c|c|c|c|c|c|c|}
\hline 30 & 56 & 55.8 & 55.9 & 57 & 57 & 57.7 & 59 & 62.7 & 89.3 & 98 & 1.36019 \\
\hline 35 & 55.8 & 55.6 & 55.9 & 57 & 56.6 & 57.1 & 58 & 60.4 & 89.9 & 102 & 1.35919 \\
\hline 40 & 56.1 & 54.5 & 53.7 & 54.4 & 55.4 & 56 & 57 & 65.1 & 90.9 & 99 & 1.35199 \\
\hline 45 & 55 & 54.6 & 54.6 & 55.4 & 55.5 & 56.3 & 56.4 & 61 & 91.4 & - & 1.36019 \\
\hline
\end{tabular}

Table (A.9): Run 9 at Power 1KW, $R=1$.

\begin{tabular}{|c|c|c|c|c|c|c|c|c|c|c|c|}
\hline Time,min & $\mathbf{T}_{\mathbf{1}} / \mathbf{c}^{\mathbf{0}}$ & $\mathbf{T}_{2} / \mathbf{c}^{\mathbf{0}}$ & $\mathbf{T}_{3} / \mathbf{c}^{\mathbf{0}}$ & $\mathbf{T}_{4} / \mathbf{c}^{\mathbf{0}}$ & $\mathbf{T}_{5} / \mathbf{c}^{\mathbf{0}}$ & $\mathbf{T}_{\mathbf{6}} / \mathbf{c}^{\mathbf{0}}$ & $\mathbf{T}_{7} / \mathbf{c}^{\mathbf{0}}$ & $\mathbf{T}_{8} / \mathbf{c}^{\mathbf{0}}$ & $\mathbf{T}_{\mathbf{9}} / \mathbf{c}^{\mathbf{0}}$ & $\Delta \mathbf{P}_{\mathbf{m m H 2 O}}$ & $\mathbf{R . I}$ \\
\hline 0 & 58.2 & 57.2 & 57 & 58.9 & 57.9 & 58.2 & 58.5 & 60.3 & 89.8 & - & - \\
\hline 10 & 57 & 55.5 & 57 & 59.4 & 58 & 59 & 58.4 & 62.3 & 90.3 & - & - \\
\hline $20, \mathrm{R}$ & 57.3 & 56.5 & 56.9 & 58 & 57.3 & 59.3 & 59 & 63.5 & 90.9 & 95 & 1.36130 \\
\hline 25 & 57 & 56.2 & 56.5 & 58.2 & 57.2 & 58.2 & 58.7 & 65.3 & 91.3 & 95 & 1.36130 \\
\hline 30 & 56.3 & 56.4 & 58 & - & - & - & - & - & 93.5 & 97.5 & 1.36019 \\
\hline 35 & - & - & - & - & - & - & - & - & 94.4 & 95 & 1.36130 \\
\hline
\end{tabular}

Table (A.10): Run 10 at Power 1KW, $R=3$.

\begin{tabular}{|c|c|c|c|c|c|c|c|c|c|c|c|}
\hline Time,min & $\mathbf{T}_{\mathbf{1}} / \mathbf{c}^{\mathbf{0}}$ & $\mathbf{T}_{2} / \mathbf{c}^{\mathbf{0}}$ & $\mathbf{T}_{\mathbf{3}} / \mathbf{c}^{\mathbf{0}}$ & $\mathbf{T}_{4} / \mathbf{c}^{\mathbf{0}}$ & $\mathbf{T}_{5} / \mathbf{c}^{\mathbf{0}}$ & $\mathbf{T}_{\mathbf{6}} / \mathbf{c}^{\mathbf{0}}$ & $\mathbf{T}_{7} / \mathbf{c}^{\mathbf{0}}$ & $\mathbf{T}_{8} / \mathbf{c}^{\mathbf{0}}$ & $\mathbf{T}_{\mathbf{9}} / \mathbf{c}^{\mathbf{0}}$ & $\Delta \mathbf{P}_{\mathbf{m m H 2 O}}$ & $\mathbf{R . I}$ \\
\hline 0 & 56.6 & 56 & 56.3 & 58.4 & 62 & 60.7 & 72.3 & 73 & 90.1 & - & - \\
\hline 10 & 55.5 & 54.8 & 54.8 & 57.8 & 70.1 & 86.8 & 88 & 90.3 & 93.7 & - & - \\
\hline 20 & 57.7 & 55 & 55.2 & 57.9 & 63.3 & 77.4 & 90.1 & 93.1 & 96.5 & - & - \\
\hline $25, \mathrm{R}$ & 55.4 & 54.6 & 55 & 56.8 & 60.1 & 69.8 & 88.9 & 93.9 & 97.8 & 97 & 1.36019 \\
\hline 30 & 55.1 & 54.8 & 56.1 & 60.1 & 76.6 & 89.6 & 94.3 & 95.8 & 98.7 & 97 & 1.36019 \\
\hline
\end{tabular}

Table (A.11): Run 11 at Power $1 \mathrm{KW}, \mathbf{R}=5$.

\begin{tabular}{|c|c|c|c|c|c|c|c|c|c|c|c|}
\hline Time,min & $\mathbf{T}_{\mathbf{1}} / \mathbf{c}^{\mathbf{0}}$ & $\mathbf{T}_{\mathbf{2}} / \mathbf{c}^{\mathbf{0}}$ & $\mathbf{T}_{\mathbf{3}} / \mathbf{c}^{\mathbf{0}}$ & $\mathbf{T}_{\mathbf{4}} / \mathbf{c}^{\mathbf{0}}$ & $\mathbf{T}_{\mathbf{5}} / \mathbf{c}^{\mathbf{0}}$ & $\mathbf{T}_{\mathbf{6}} / \mathbf{c}^{\mathbf{0}}$ & $\mathbf{T}_{\mathbf{7}} / \mathbf{c}^{\mathbf{0}}$ & $\mathbf{T}_{\mathbf{8}} / \mathbf{c}^{\mathbf{0}}$ & $\mathbf{T}_{\mathbf{9}} / \mathbf{c}^{\mathbf{0}}$ & $\Delta \mathbf{P}_{\mathbf{m m H} \mathbf{2}}$ & $\mathbf{R . I}$ \\
\hline 0 & 53.2 & 53.3 & 54.4 & 56 & 55.5 & 57.5 & 60 & 74 & 90.5 & - & - \\
\hline 10 & 57 & 55 & 56.2 & 60 & 80 & 88 & 90 & 92 & 93 & - & - \\
\hline 20 & 64 & 57 & 58 & 61.6 & 76 & 89 & 92 & 93 & 96.5 & - & - \\
\hline $25, \mathrm{R}$ & 60 & 61 & 59 & 62.8 & 75 & 93 & 94 & 95 & 97.7 & 102 & 1.36019 \\
\hline 30 & 62 & 64 & 62 & 67 & 90 & 93 & 97 & 98 & 98.5 & 106 & 1.36019 \\
\hline 35 & 56.5 & 56.2 & 58.3 & 63.8 & 80.3 & 93 & 97 & 98 & 99.5 & 104 & 1.35919 \\
\hline 40 & 57 & 66 & 73 & 82 & 87 & 97 & 99 & 100 & 100 & 107 & 1.35919 \\
\hline 45 & 60 & 60 & 72 & 98 & 99 & 100 & 99 & 100 & 101 & 95 & 1.36019 \\
\hline
\end{tabular}


Table (A.12): Run 12 at Power 1KW, R =7.

\begin{tabular}{|c|c|c|c|c|c|c|c|c|c|c|c|}
\hline Time, $\mathbf{m i n}$ & $\mathbf{T}_{\mathbf{1}} / \mathbf{c}^{\mathbf{0}}$ & $\mathbf{T}_{\mathbf{2}} / \mathbf{c}^{\mathbf{0}}$ & $\mathbf{T}_{\mathbf{3}} / \mathbf{c}^{\mathbf{0}}$ & $\mathbf{T}_{\mathbf{4}} / \mathbf{c}^{\mathbf{0}}$ & $\mathbf{T}_{\mathbf{5}} / \mathbf{c}^{\mathbf{0}}$ & $\mathbf{T}_{\mathbf{6}} / \mathbf{c}^{\mathbf{0}}$ & $\mathbf{T}_{\mathbf{7}} / \mathbf{c}^{\mathbf{0}}$ & $\mathbf{T}_{\mathbf{8}} / \mathbf{c}^{\mathbf{0}}$ & $\mathbf{T}_{\mathbf{9}} / \mathbf{c}^{\mathbf{0}}$ & $\Delta \mathbf{P}_{\mathbf{m m H 2 O}}$ & $\mathbf{R . I}$ \\
\hline 0 & 57 & 58.9 & 57.4 & 62.6 & 54.2 & 63.2 & 65.3 & 65.5 & 92.3 & - & - \\
\hline 10 & 59.1 & 59 & 59.5 & 61.7 & 75.7 & 88.1 & 95 & 95.9 & 95.6 & - & - \\
\hline 15 & 56.3 & 55.5 & 56.4 & 61.5 & 86.5 & 93.9 & 94.3 & 96.2 & 97.3 & - & - \\
\hline $20, \mathrm{R}$ & 57 & 56.4 & 57 & 64.1 & 91.6 & 95.1 & 96 & 97.7 & 98.3 & 104 & 1.3622 \\
\hline 25 & 56.8 & 56 & 57.5 & 62.5 & 88.2 & 93.2 & 96.4 & 98.1 & 99.2 & 105 & 1.36019 \\
\hline 30 & 56.8 & 55.9 & 57.8 & 64.1 & 92.9 & 96.3 & 97.6 & 99.1 & 99.9 & 110 & 1.36019 \\
\hline 35 & 57.4 & 56.7 & 60.3 & 76.1 & 96.1 & 98.5 & 98.1 & 99.7 & 100.5 & 105 & 1.35919 \\
\hline 40 & 58 & 57.2 & 63 & 91.1 & 98.7 & 99.4 & 98.6 & 99.9 & 100.8 & 105 & 1.36130 \\
\hline
\end{tabular}

